\title{
Mössbauer spectroscopy and Rietveld refinement used to analyze stainless steel properties regarding shape memory effect (SME)
}

\author{
José Flávio Marcelino Borges ${ }^{1}$, Fabiana Cristina Nascimento Borges ${ }^{1}$
}

\author{
${ }^{1}$ Department of Physics - State University of Ponta Grossa- Av. Carlos Cavalcanti 4748, 84030-900, Ponta Grossa, Para- \\ na, Brazil. \\ e-mail: fborges@uepg.br, fabianacristinanascimento@gmail.com
}

\begin{abstract}
The resonant absorption of recoilless $\gamma$-rays, known as Mössbauer Spectroscopy, is an efficient nuclear prospecting technique to structural and magnetic analysis. When studying steels, it is possible to accurately analyze the surface of materials using the Conversion Electron Mössbauer Spectroscopy technique (CEMS) that evaluates the sample's surface to a depth of $200 \mathrm{~nm}$, and by Conversion X-ray Mössbauer Spectroscopy by (CXMS), which can go deeper and investigate inner layers of steel samples $(10 \mu \mathrm{m})$. In this work, this technique was employed to study the crystallographic reversion (f.c.c. $\rightarrow$ h.c.p.) of stainless steel shape memory. A hexagonal martensitic phase was induced mechanically through the compression test and the reversion to austenite phase was observed using heat treatment. Mössbauer spectroscopy measurements were carried out using the conversion of electrons, and X-ray with a ${ }^{57}$ Co source in a rhodium matrix at room temperature and without the external fields. Spectra were analyzed using specific adjustment software. The results indicated great reversal of $\varepsilon$-martensite. Rietveld refinement analysis was obtained using the XRD data to evaluate possible structural changes occurring during the thermo-mechanical treatment (cycles of deformation followed by heating). Comparison of the Mössbauer spectra and Rietveld refinement are important for understanding the reversal of the martensitic phase. In this case, the crystal structure changes resulted in a shape recovery material, which was deformed beyond its elastic limit.
\end{abstract}

Keywords: Shape memory effect, stainless steel, $\varepsilon$-martensite, Mössbauer Spectroscopy, Rietveld refinement.

\section{INTRODUCTION}

Stainless steel is gaining increasingly widespread usage in a range of engineering applications as a constructional material and for a wide range of applications in chemical, petrochemical, thermal and nuclear power industries. These alloys exhibit good mechanical properties at elevated temperatures and ease of fabrication, including welding, and outstanding resistance to corrosion [1,2] On the other hand shape memory alloy can be used in areas where conventional technologies (e.g., hydraulic, pneumatic, or electric motors) are deemed unsuitable. As such, unexplored aircraft, control surfaces, spacecraft mechanisms, oil drilling rigs, and other devices can be revisited and evaluated for enhanced benefits. [3, 4]

Alloys with the shape memory effect (SME) present the capability of recovering their original shape after being deformed beyond their elasticity limit. The physical phenomenon is related to the crystallographically reversible martensite transformation. There are several techniques used to analyze their shape recovery performance. Such materials are known as intelligent materials. The analyses comprise macroscopic, microscopic and nanometric scales. Fe-Mn-Si-Cr-Ni-(Co) based alloys has been studying employing techniques such as mechanical tests (traction/compression), scanning electronic and optical microscopy, Rietveld refinement, Mössbauer spectroscopy and instrumented indentation. Preliminary results pointed to two important conclusions: (1) the refinement of initial microstructure (austenitic grain) contributed to improve the Fe based alloys shape recovery performance; and (2) the reversion to the austenitic phase is enhanced due to the absence of martensite- $\alpha$ '(c.c.c) phase in samples with refined granulometry, favoring the Shockley partial dislocation reverse movement [5]. Besides this, the variation in the volumetric fraction of the austenite and martensite ( $\varepsilon$ e $\alpha$ ') phases directly influenced the mechanical properties [6]. 
Proceeding with this study, in this work the hyperfine interactions between stainless alloy and SME are studied using Mössbauer spectroscopy aiming to investigate the formation and reversion of the martensite phase. It is a highly accurate experimental technique which uses the energy emitted in transitions between nuclear states. With such technique, it is possible to evaluate this effect in several materials due to their nuclear magnetic interactions, as well as to verify the electronic distribution around the atom in a crystalline structure. Thus, it is possible to identify qualitatively the presence of impurities and structural deformation. Two kinds of geometry can be employed to obtain the information via Mösbauer spectroscopy: the transmission geometry, usually used to analyze the powders, and the conversion geometry applied to thick massive materials. From the latter, data can be collected through Conversion Electron Mössbauer Spectroscopy (CEMS) and Conversion X-ray Mössbauer Spectroscopy (CXMS). The difference between these measurements is in the fact that the electrons which are extracted from the sample and reach the detector usually come from the surface and the CEMS technique prospection depth is around $200 \mathrm{~nm}$. The CXMS enables a deeper radiation collection (about $10 \mu \mathrm{m}$ ). Thus, by employing both techniques, it is possible to evaluate two layers at different depths in a sample. In general, Mössbauer spectroscopy is a very important technique in the metal industry covering several research areas such as corrosion properties studies, nitrided steel surfaces [7], phase transformation [8], Fe addition in the martensite transformation [9], investigation of shape memory alloys [10] among others. Particularly on the Fe based stainless alloy with SME, there is few data in literature. Preliminary data of this study, indicating a relationship between hyperfine and structural interactions of this alloy has been recently analyzed [11].

In this study, the Fe-Mn-Si-Cr-Ni-Co based alloy was evaluated comparing the hyperfine and structural properties. The results complement existing data about mechanical properties and shape recovery in literature.

\section{MATERIALS AND METHODS}

The stainless alloy, similar to the AISI 304 steel, with SME was elaborated in previous studies [12] and presents the following chemical composition: (\% in weight): 0.009C-5.25Si-8.26Mn-0.002P-0.006S-11.84Co$12.81 \mathrm{Cr}-5.81 \mathrm{Ni}-0.001 \mathrm{Mo}-0.16 \mathrm{Cu}-50 \mathrm{O}_{2} *-52 \mathrm{~N}_{2} *$ (* content in ppm). Samples were prepared for compression tests to introduce the martensitic transformation mechanically. The SME was verified after thermal treatment at $600^{\circ} \mathrm{C}[5,11]$. The samples were submitted to a six-cycle thermomechanical test. Each cycle corresponded to compression testing (to induce $\varepsilon$-martensite) followed by heating (to recover shape memory). The surface morphology was evaluated through optical microscopy in samples that had been previously sanded, polished and etched with specific reagents. The sanding was done until sandpaper \# 1200 and diamond polishing was used up to $0.25 \mu \mathrm{m}$. The reagent: $2 \mathrm{ml} \mathrm{HCl}, 2 \mathrm{ml} \mathrm{HNO}, 1 \mathrm{ml}$ glycerin was used to reveal the grain contours, deformation patterns and martensite plates. To identify the martensites $\varepsilon$ (h.c.) and $\alpha$ '(c.c.c) resulting from the transformation $\gamma$ (c.f.c.) $\rightarrow \varepsilon$ (h.c.) $\rightarrow \alpha^{\prime}$ (c.c.c), $20 \mathrm{~g} \mathrm{~K} 2 \mathrm{~S} 2 \mathrm{O} 5+0.5 \mathrm{~g} \mathrm{NH} 4 \mathrm{HF} 2+$ $100 \mathrm{ml}$ of $\mathrm{H} 2 \mathrm{O}$ was used. Structural variations were observed using Rietveld refinement from X-ray diffraction data (XRD) collected in a diffractometer PW1710-Philips employing CuK $\alpha$ radiation at room temperature.

The following conditions were kept throughout the spectra collection: $0.02^{\circ}$ step and $2 \mathrm{~s}$ counting time. The JCPDS cards and the Inorganic Crystal Structure Database were used for the identification of phases and for the initial structural refinement parameters. The structural parameter changes in the phases (lattice parameters and unitary cell volume) were evaluated with Rietveld refinement using the program FullProf [13, 14]. The pseudo-Voigt adjustment function was used in all analyses. The shape, position and width of reflexions were adjusted from the refinement parameters $[13,14]$. Results were evaluated taking into consideration the austenitic grain size.

Conversion Electron Mössbauer Spectroscopy measurements (CEMS) were carried out using standard equipment and a ${ }^{57} \mathrm{Co}$ source with gama radiation characteristic of $14,4 \mathrm{keV}$, at room temperature and using a Rikkon proportional counter with methane helium constant flow. The Conversion X-ray Mössbauer Spectroscopy (CXMS) measurements were performed using a constant methane argon flow at room temperature and measured with a standard proportional counter. The equipment calibration was obtained using pure metallic iron sheets and data adjusted with an adjustment program developed at the UFRGS Physics Institute using Gaussian discrete lines.

In this work, 3 samples with different number of cycles ( 1 cycle, 3 cycles and 6 cycles) were investigated, making it possible to evaluate if there is a difference in the evolution of the samples during the compression and heat treatment processes. 


\section{RESULTS AND DISCUSSIONS}

Fig. 1 presents the Rietveld refinement for AISI 304 commercial austenitic steel. The main phase identified was austenite- $\gamma$ and a very little fraction of the phase martensitic- $\alpha$ ' induced by deformation was also identified in the diffractograms. The austenite phase was identified through the JCPDS 33:0397 card, a centered face cubic structure, spatial group 229. The martensite- $\alpha$ ' phase is often identified in commercial austenitic steels when submitted to deformation. Regarding SME submitted to low deformation, the following transformation sequence is usual: $\gamma$ (c.f.c.) $\rightarrow \varepsilon$ (h.c.) $\rightarrow \alpha^{\prime}$ (c.c.c) [6]. The diffractogram presented in Fig. 1 and the phases' structural characteristics are very similar to the stainless alloy with SME investigated in this study, as can be seen in Fig. 2.

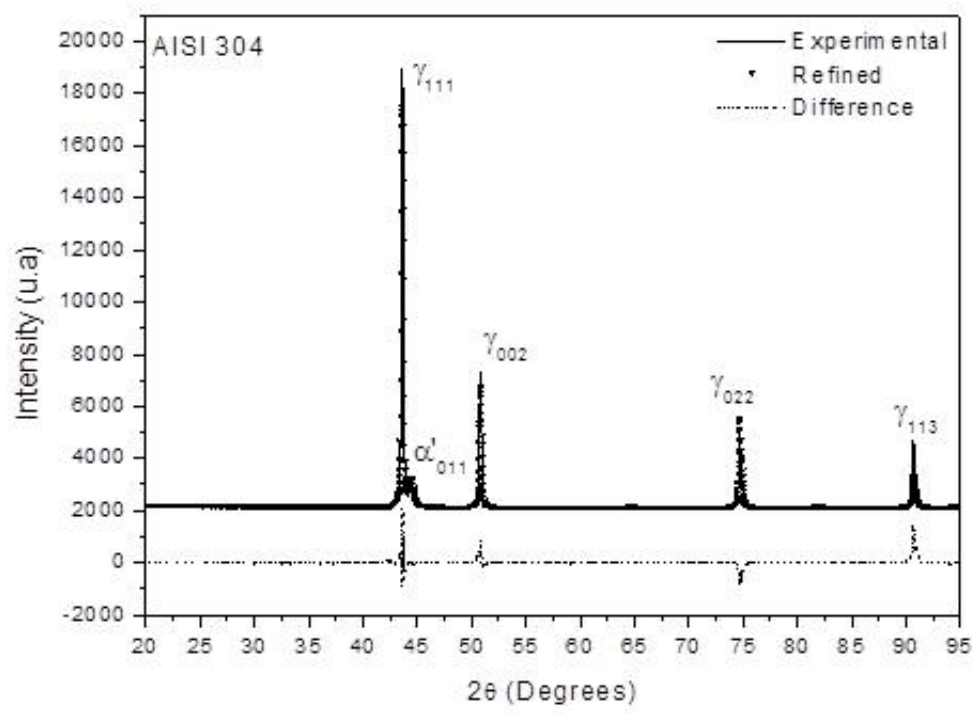

Figure 1: Rietveld Refinement for AISI 304 austenitic steel.

Fig. 2 presents the Rietveld refinement of the steel sample with SME, deformed state (prior to shape recovery). Three diffractograms are presented: (a) experimental (obtained straight from the diffractometer), (b) Refined (spectra adjustment result based on adjustment of structural parameters) and (c) Difference (difference between experimental and refined diffractograms, indicating the refinement quality). This analysis indicated the presence of austenite- $\gamma$ e martensite- $\varepsilon$ phases. Unlike commercial steel (Fig. 1), the alloy with SME (Fig. 2) did not present the phase martensite- $\alpha$ ' phase, which refers to the deformation level as well as the stacking fault energy. Samples with larger sized austenitic grains (about1 $30 \mu \mathrm{m}$ ) also presented the same phases indicated in Fig. 2. Regarding the study of alloys with SME, the main information of the Rietveld refinement is the variation of lattice parameters of the unitary cell $c$ and a in the martensite- $\varepsilon$ phase. Such alterations are better seen from the c/a ratio of the martensite- $\varepsilon$ phase, as this parameter is directly related to the shape recovery as well as to mechanical properties. Fig. 3 presents this variation as a function of the grain size and the number of training cycles. Each cycle corresponded to compression deformation to induce the martensite- $\varepsilon$ phase followed by heating at $600^{\circ} \mathrm{C} / 30$ minutes in order to recover the shape [5]. 


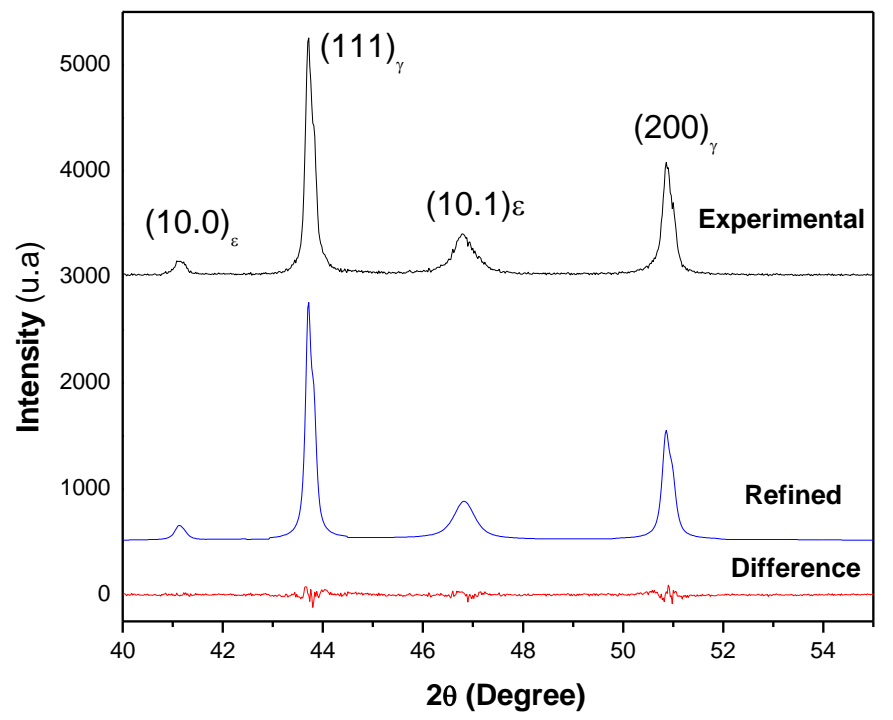

Figure 2: Rietveld refinement and identification of austenite- $\gamma$ and martensite- $\varepsilon$ phases for the steel with SME sample.

It could be seen that in all cycles, the sample with the smallest grain size presenting higher c/a variation, contributing to better recovery of the martensitic phase during heating [5]. At the top of Fig. 3, an optical microscopy image is presented which reveals morphological aspects of the alloy, very similar to any austenitic steel without SME. The reagent Nital, largely used in steels, identifies the grain boundaries, the austenitic and martensitic phases are observed as lamellas distributed within the austenitic grain. Another aspect to be taken into account is the deformation bands (wider lamellas) within the austenitic grain, very common in steels. In a coarser microstructure of this alloy it is possible to observe variation towards the martensite- $\varepsilon$ lamellas, and in some cases some overlapping creating nucleation points for the martensite- $\alpha$ 'phase. According to previously published results [5]

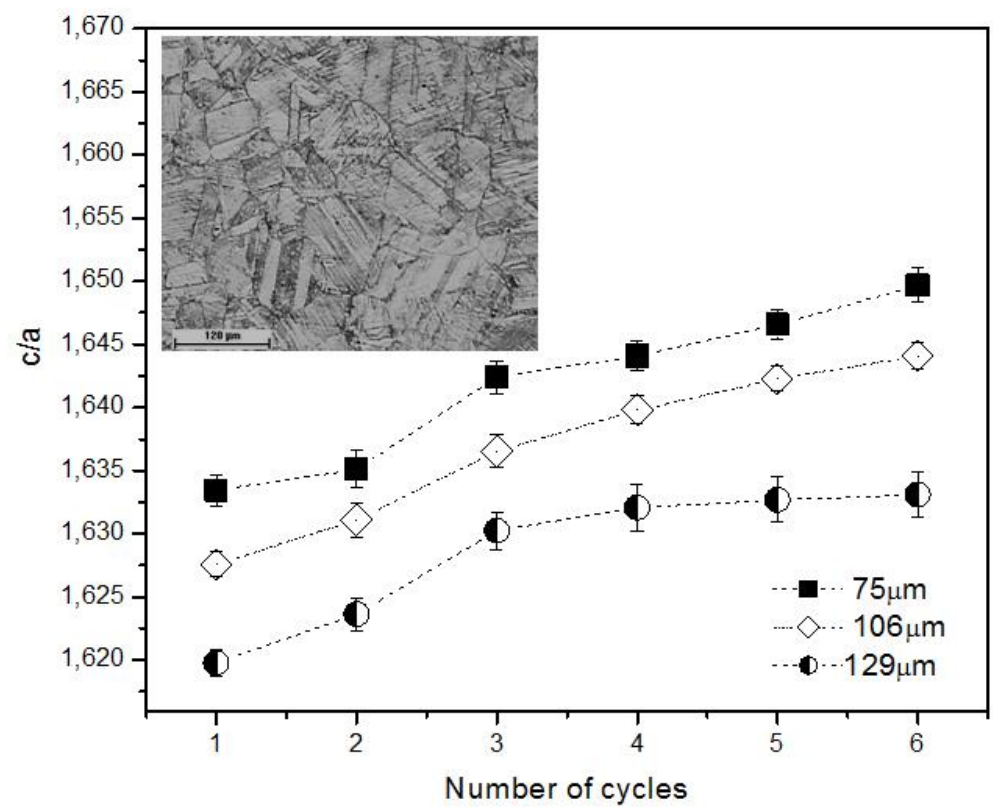

Figure 3: (a) Variation of martensitic- $\varepsilon$ phase parameters. Top: optical microscopy showing aspects of the stainless alloy with SME morphology (Reagent: Nital 2\%, attack made by immersing the sample, for 20 seconds). 
Fig. 4 shows the spectra obtained through the Conversion Electron Mössbauer Spectroscopy. It is easy to see that an only site with paramagnetic characteristics, typical of austenite, can be identified, regardless of the treatment given to the samples. In Fig. 5 CXMS spectra are presented in full agreement with Fig. 4 at greater depth. In these spectra the circles represent experimental data obtained while the continuous lines that cross the circles come from theoretical adjustments. Although the spectra obtained through CXMS presented a wide base line it was not possible to use parameters related to the martensite or any other iron site to adjust and identify another phase different from the central singlet austenitic phase.

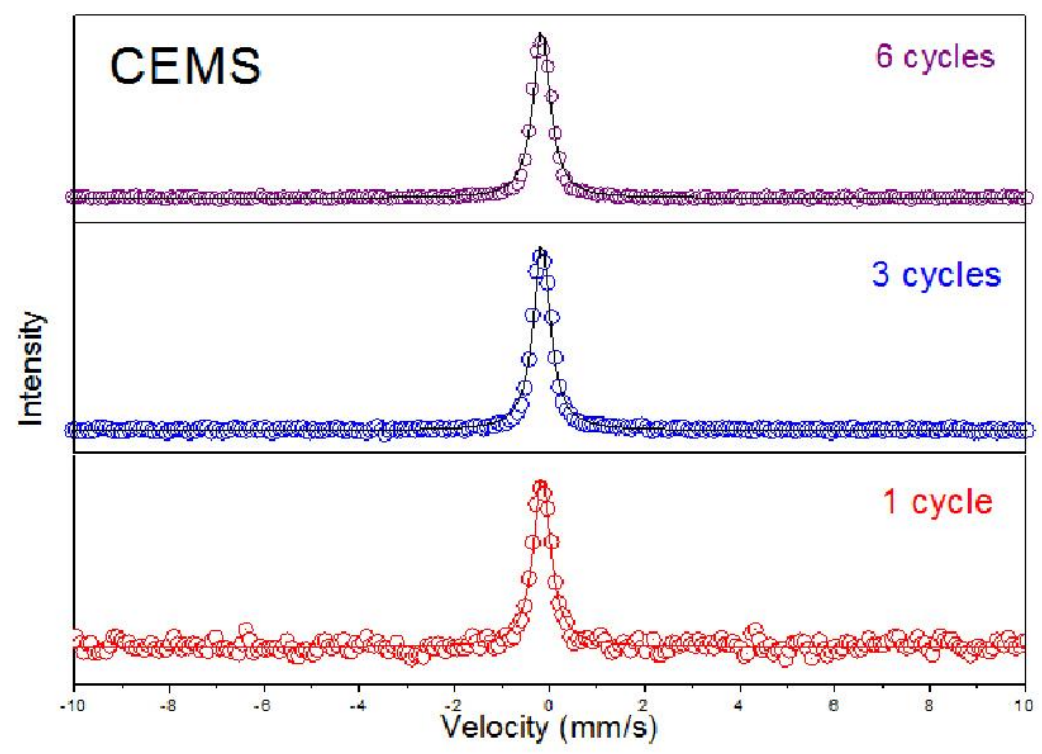

Figure 4: Mössbauer Spectroscopy - CEMS, recovered state.

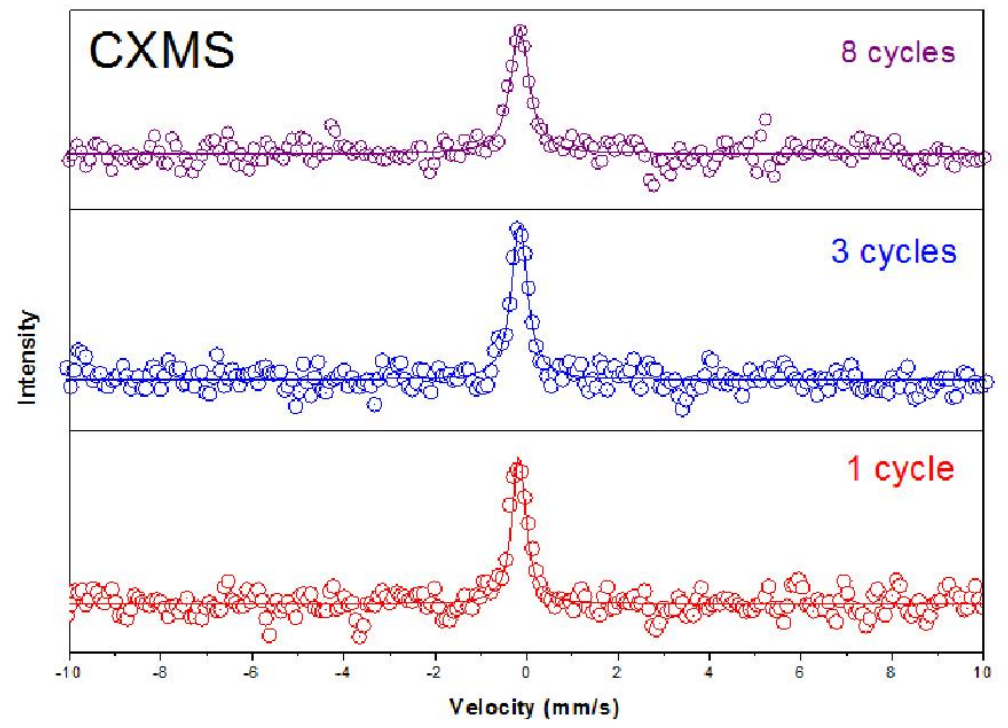

Figure 5: Mössbauer Spectroscopy - CXMS, recovered state.

Tables 1 and 2 present the adjustment parameters for the samples under study. In all spectra, the hyperfine fields $\left(\mathrm{B}_{\mathrm{hf}}\right)$ and quadrupole splitting $(\Delta \mathrm{Eq})$ are zero. Isomer Shift relative of $\alpha \mathrm{Fe}$ (IS) are very similar, indicating the same phase (austenite) in all samples. The resonance line width $\Gamma$ indicate the existence of an only phase. 
Table 1: Mössbauer Parameters - CEMS

\begin{tabular}{ccccc}
\hline Sample & $\mathbf{B}_{\text {hf }}(\mathrm{kOe})$ & $\Delta \mathbf{E q}(\mathrm{mm} / \mathrm{s})$ & $\mathbf{I S}(\mathrm{mm} / \mathrm{s})$ & $\Gamma(\mathrm{mm} / \mathrm{s})$ \\
\hline 1 cycle & 0 & 0 & $-0,162$ & 0,431 \\
\hline 3 cycles & 0 & 0 & $-0,164$ & 0,422 \\
\hline 6 cycles & 0 & 0 & $-0,169$ & 0,426 \\
\hline
\end{tabular}

Table 2: Mössbauer Parameters - CXMS

\begin{tabular}{ccccc}
\hline Sample & $\mathbf{B}_{\mathbf{h f}}(\mathrm{kOe})$ & $\Delta \mathbf{E q}(\mathrm{mm} / \mathrm{s})$ & $\mathbf{I S}(\mathrm{mm} / \mathrm{s})$ & $\Gamma(\mathrm{mm} / \mathrm{s})$ \\
\hline 1 cycle & 0 & 0 & $-0,171$ & 0,358 \\
\hline 3 cycles & 0 & 0 & $-0,58$ & 0,405 \\
\hline 6 cycles & 0 & 0 & $-0,151$ & 0,472 \\
\hline
\end{tabular}

Results presented in Figures 4 and 5 indicated excellent reversion in the alloy with SME during heating. Through Fig. 6, the same conclusion is reached observing X-ray diffractograms of samples with different grain sizes after shape recovery [5]. Results, evaluated in previous studies, indicated clearly the reversion from the martensite- $\varepsilon$ phase to austenite, as presented in Figures 4, 5 and 6 . The reflexion $(10.1)_{\varepsilon}$ practically disappears when compared to the deformed state (transformation $\gamma \rightarrow \varepsilon$ ). This reversion to the austenitic phase during heating is responsible for the material shape recovery.

In summary, the results presented here indicate that this alloy has an excellent capacity for restoration when subjected to heat treatment, taking into account that the Mossbauer spectroscopy technique is a nuclear analysis technique and, therefore, very sensitive. In addition, two depth profiles were scanned with electron conversion and x-ray spectroscopy. This indicates that not only the surface of the work has been restored with the heat treatment. This results is in resonance with other works reported in the literature, obviously using a different treatment than the one used in the present work. [15]

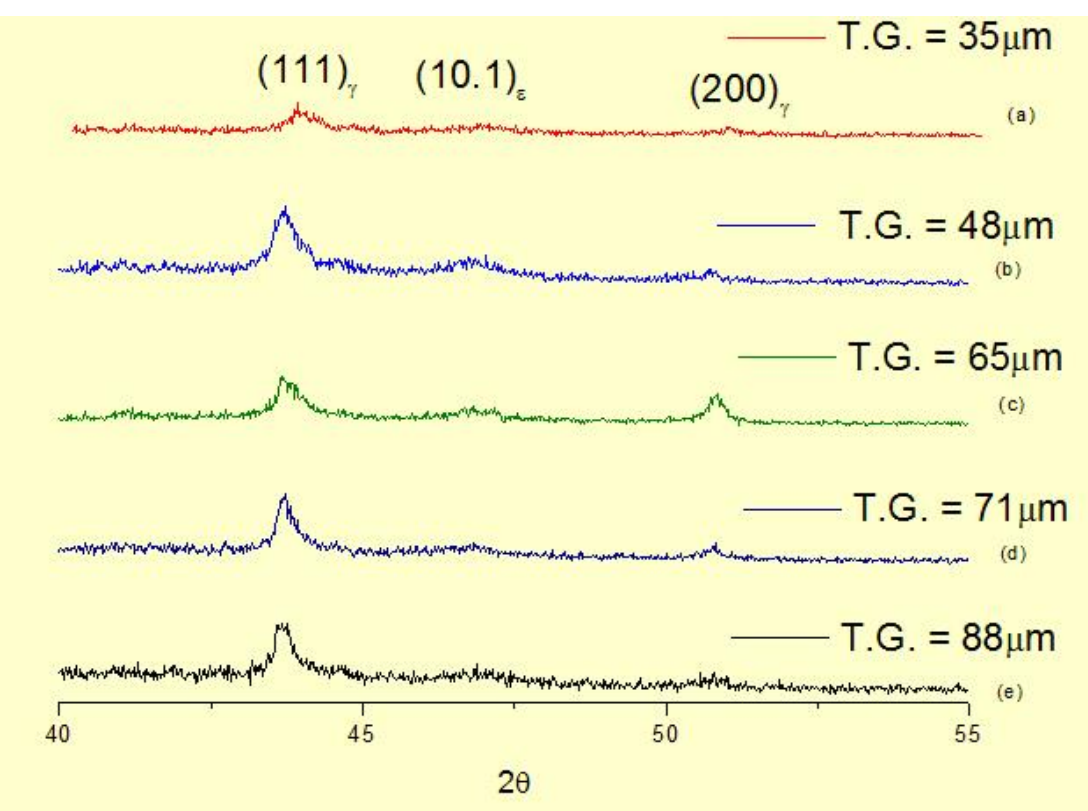

Figure 6: Spectrum of X-ray diffraction of samples with SME with different grain sizes after shape recovery (NASCIMENTO, 2008). 


\section{CONCLUSIONS}

Using Mössbauer Spectroscopy (CEMS and CXMS) in all samples after shape recovery, it was possible to observe hyperfine parameters that were very similar to each other, which in this case refer to the austenitic phase. This phase was detected from an only site with paramagnetic characteristics. This result is interesting and complements data analyzed through the Rietveld refinement, indicating good performance in terms of shape recovery for this composition. XRD data indicated higher reversion for samples with smaller austenitic grain size. Higher variation in lattice parameters (c and a) through the c/a ratio for the martensite phase was observed in samples with grain size of about $75 \mu \mathrm{m}$ indicating that the higher the c/a variation is, the easier it is for the reversion $\varepsilon \rightarrow \gamma$ to occur, pointing to an increased shape recovery performance of these materials.

\section{ACKNOWLEDGEMENTS}

Authors are thankful to the financial support of CNPq and Fapesp.

\section{REFERENCES}

[1] ARRAYAGO, I., REAL, E., GARDNER, L. "Description of stress-strain curves for stainless steel alloys", Material \& Design, v. 87, pp. 540-552, 2015.

[2] EZUBER, H., ALSHATER, A., NISAR, et al., "Effect of surface finish on the pitting corrosion behavior of sensitized AISI 304 austenitic stainless steel alloys in $3.5 \% \mathrm{NaCl}$ solutions", Surface Engineering and Applied Electrochemistry v. 54, n. 1, pp. 73-80, 2018.

[3] BENAFAN, O., GAYDOSH, D. J. "Constant-torque thermal cycling and two-way shape memory effect in ni 50.3 ti 29.7 hf 20 torque tubes”, Smart Materials and Structures, v. 27, n. 7, pp. 075035 - 075044, 2018. [4] WANG, J., LI, Q., XIONQ, C., et al., "Effect of Zr on the martensitic transformation and the shape memory effect in Ti-Zr-Nb-Ta high-temperature shape memory alloys", Journal of Alloys and Compounds $\mathrm{v}$. 737, pp. 672-677, 2018.

[5] NASCIMENTO, F.C., Ligas austeníticas com memória de forma. Influência da microestrutura nas propriedades mecânicas e na recuperação de forma, 1 ed., Edgar Blucher, 2008.

[6] OTUBO, J., NASCIMENTO, F.C., MEI, P.R., et al., "Influence of austenite grain size on mechanical properties of stainless SMA”, Materials Transactions, v. 43, n. 5, pp. 916-919, 2002.

[7] SOUZA, S.D., OLZON-DIONYSIO, M., BASSO, R.L.O., et al., "Mössbauer spectroscopy study on the corrosion resistance of plasma nitride ASTM F 138 stianless steel in chloride solution", Materials Characterization, v. 61, n. 10, pp. 992-999, 2010.

[8] SUAVAGE, X., LE BRETON, J.M.L., GUILLET, A., et al., "Phase transformations in surface layers of machined steels investigated by x-ray diffraction and Mössbauer spectrometry", Materials Science and Engineering A, v. 362, n. 1-2, pp. 181-186, 2003.

[9] SINGH, R.K., RAJA, M.M., MATHUR, R.P., et al., "Effect of Fe substitution on the phase stability and magnetic properties of Mn-rich Ni-Mn-Ga ferromagnetic shape memory alloys”, Journal of Magnetism and Magnetic Materials, v. 323, n. 5, pp. 574-578, 2011.

[10] RAI, D.K., YADAV, T.P., SUBRAHMANYAM, V.S., et al., "Structural and Mössbauer spectroscopic investigation of Fe substituted Ti-Ni shape memory alloys", Journal of Alloys and Compounds, v. 482, n. 12, pp. 28-32, 2009.

[11] NASCIMENTO, F.C., MEI, P.R., OTUBO, J. "Estudo do efeito de memória de forma em ligas inoxidáveis usando ensaio de compressão”, Revista Escola de Minas, v. 63, pp. 493-499, 2010.

[12] OTUBO, J., KOSHIMIZU, S. "Production and characterization of stainless steel based Fe-Cr-Ni-Mn-Si(Co)”, Journal of Physique, IV, C8, v. 5, pp. 427-432, 1995.

[13] RIETVELD, H.M.A. "Profile refinement method for nuclear and magnetic structure", Journal of Applied Crystallography, v. 2, pp. 65-71, 1969.

[14] CARVAJAL J.R. An introduction to the program Full Prof. in: Laboratoire Léon Brillouin, França, 2001. 
[15] CHEN, J., PENG, H., WANG, S., DU, Y., et al., "Remarkable improvement of shape memory effect in austenitic stainless steel by thermo-mechanical training", Advanced Engineering Materials, v. 17, n. 3, pp. 330-333, 2015.

\section{ORCID}

José Flávio Marcelino Borges

Fabiana Cristina Nascimento Borges https://orcid.org/0000-0002-1677-3118

in memorian. 